\title{
Sistem Informasi Penyebaran Lokasi Pelatihan Desa Berbasis GIS di Balai Besar Pengembangan Latihan Masyarakat Jakarta
}

\author{
Anhar Hawari*, Agung Triayudi, Ira Diana Sholihati \\ Fakultas Teknologi Komunikasi dan Informatika, Informatika, Universitas Nasional, Jakarta, Indonesia \\ Email: 1,*anharhawari3@gmail.com, ${ }^{2}$ agungtriayudi@ civitas.unas.ac.id, ${ }^{3}$ iradiana2803@gmail.com \\ Email Penulis Korespondensi: anharhawari3@gmail.com
}

\begin{abstract}
Abstrak-Balai Besar Pengembangan Latihan Masyarakat Jakarta merupakan salah satu unit kerja di Kementerian Desa, PDT, dan Transmigrasi yang memiliki tugas dan fungsi untuk melatih masyarakat desa. Setiap tahunnya masyarakat yang dilatih dapat mencapai ribuan orang yang terdiri dari beberapa desa. Karena perkembangan teknologi informasi, saat ini peta dapat ditampilkan secara digital dengan menggunakan Sistem Informasi Geografi (SIG), agar lebih efisien dan mudah diakses oleh siapapun dan dimanapun, peta digital ini akan diintegrasikan menggunakan web. Penelitian ini akan dikembangkan menggunakan kerangka website HTML,CSS dan Javascript sebagai front end, PHP sebagai backend dan MySQL dengan memanfaatkan fitur phpMyAdmin sebagai basis data, semua bahasa pemrograman tersebut akan diolah menggunakan Framework Codeigniter. Hasil akhir penelitian ini akan berupa Sistem Informasi Geografi persebaran pelatihan dengan menampilkan lokasi pelatihan, data pelatihan, serta data dokumentasi berbentuk video saat pelatihan berlangsung, data tersebut akan disajikan dalam bentuk Google Maps sehingga dapat dengan mudah menemukan lokasi pesebaran pelaksanaan pelatihan yang nantinya dapat digunakan sebagai acuan untuk menentukan lokasi pelatihan berikutnya.
\end{abstract}

Kata Kunci: SIG, Codeigniter, Pelatihan, Desa, Website

\begin{abstract}
Jakarta Large Community Development Training Center is one of the work units in the Ministry of Villages, Disadvantaged Regions Development and Transmigration, that has the task and function to train rural communities. Every year the community trained can reach thousands of people consisting of several villages. Because the development of information technology maps can be displayed digitally by using Geographic Information Systems (GIS), so that it is more efficient and easily accessed by anyone and anywhere, this digital map will be integrated using the web. This research will be developed using HTML, CSS and Javascript website frameworks as front end, PHP as backend and MySQL by utilizing phpMyAdmin features as a database, all the programming languages will be processed using Codeigniter Framework. The final results of this study will be a Geographic Information System form for training distribution by displaying training locations, training data, as well as video documentation when training takes place, the data will be presented in Google Maps form so that it can easily find the location of training deployments that can later be used as a reference to determine the next training location.
\end{abstract}

Keywords: GIS, Codeigniter, Training, Village, Website

\section{PENDAHULUAN}

BBPLM Jakarta merupakan salah satu unit kerja yang berada di bawah Kementerian Desa, PDT, dan Transmigrasi, BBPLM Jakarta memiliki tugas dan fungsi untuk melakukan pelatihan untuk masyarakat desa, setiap tahunnya BBPLM Jakarta dapat melatih ribuan masyarakat dari beberapa desa/kelurahan di wilayah DKI Jakarta, Jawa Barat, Banten, Kep. Bangka Belitung, Lampung, dan Sumatera Selatan. untuk mendukung efektifitas penentuan lokasi pelatihan agar pelatihan dapat dilaksanakan secara merata, maka diperlukan Sistem Informasi Geografis yang dapat menampilkan penyebaran pelatihan yang telah dilaksanakan yang digunakan sebagai acuan dalam menentukan lokasi pelatihan berikutnya berdasarkan hasil output Sistem Informasi Geografis. Seiring berkembangnya zaman teknologi informasi juga semakin berkembang.

Di era milineal ini tantangan yang dihadapi oleh kelompok organisasi yaitu tantangan untuk memaksimalkan potensi yang ada dengan tujuan agar potensi tersebut dapat menyediakan informasi yang cepat, relevan, dan cukup akurat [1]. salah satu pemanfaatan perkembangan teknologi informasi yaitu pemanfaatan website, website terdiri dari kumpulan beberapa situs atau halaman dimana terdapat sebuah domain atau sub domain yang merangkum website tersebut. Di internet, website memiliki tempat yang berada didalam World Wide $W e b(W W W)[2]$. Manfaat dari penggunaan website itu sendiri adalah dapat mengelola data dengan otomatis, selain itu website merupakan software yang menggunakan teknologi internet sehingga dapat digunakan kapanpun dan diamanapun. Salah satu pemanfaatan website yaitu dengan mengimplementasikan WebGIS ke dalam website, Web-based GIS atau sering disingkat WebGis merupakan sebiah Sistem Informasi Geografis yang didistrbusikan memlalui jaringan komputer dengan tujuan untuk mengintegrasikan informasi geografi dengan output berupa visual [3].

Menurut Riyanto yang dikutip oleh Sholikhan, dkk, secara sederhana WebGIS dapat dirtikan sebagai penggabungan antara pemetaan dan web desain [4]. Untuk konfigurasinya, WebGIS memiliki server dimana server tersebut memiliki fungsi sebagai Map Server, server tersebut memiliki tugas untuk memproses permintaan peta yang diminta client lalu mengirimkannya kembali kepada client [5]. Sistem Informasi Geografis sangat penting untuk menangani masalah yang sifatnya menyebar, menurut Fraile yang dikutip oleh Zheng, et al, menyatakan bahwa Sistem Informasi Geografis memliki peran yang cukup penting dalam menyelesaikan perencanaan instalasi serta masalah manajemen yang bersifat kompleks [6]. 
Selain itu aplikasi sistem GPS dan GIS saat ini adalah alat yang cukup penting dalam memantau, mengelola serta memperbarui atau mengupdate informasi dalam skala harian, bulanan bahkan tahunan [7]. Contoh penerapan WebGIS yang saat ini paling banyak digunakan adalah Google Maps selain itu aplikasi WebGIS lain seperti arcgis dan OpenStreetMap juga banyak digunakan untuk membuat WebGIS. Dalam perancangan aplikasi WebGIS ini, akan memanfatkan HTML sebagai frontend, menurut Hidayatullah yang dikutip oleh Fitri A, HTML atau yang sering disebut dengan Hypertext Merkup Langguage merupakan bahasa yang paling umum atau standart yang diimplementasikan untuk menampilkan halaman pada website [8], selain HTML, dibagian frontend akan digunakan CSS untuk memberi tampilan yang lebih menarik, selain itu pada pembuatan WebGIS ini diperlukan pahasa pemrograman Javascript, hal ini dikarenakan apikasi peta web umumnya divisualisasikan menggunakan Javascript [9]. Kemudian pada bagian backend akan digunakan bahasa pemrograman PHP. Alasan menggunakan PHP karena Menurut M. Hills yang dikutip oleh Douglas bahasa pemrograman PHP pada saat ini adalah salah satu bahasa pemrograman yang banyak digunakan oleh komunitas Open Source serta industri untuk membangun perangkat lunak berskala besar baik berbasis web ataupun aplikasi lainnya [10]. Kemudian untuk databasenya menggunakan MySQL, MySQL adalah sebuah perangkat lunak untuk memanajemen basis data menggunakan SQL (DBMS) yang bersifat multithread dari basis data yang bersifat relasional (RDBMS) [11]. Alasan mengapa menggunakan MySQL dibandingkan dengan database yang lain yaitu karena sifatnya yang Open Source, Menurut Coppla dan Neely yang dikutip oleh jaafar, et al Open Source atau sering disebut Open Source Software merupakan kode sumber yang bersifat terbuka dimana siapapun bebas untuk menggunakan baik untuk dipelajari, ditambah, ataupun direvisi ulang [12].

Kemudian untuk membangun sistem dan menggabungkan seluruh bahasa pemrograman yang dipilih digunakan framework Codeigniter. Menurut Beta Sidik yang dikutip oleh Mara dan Qadhili, Framework adalah kumpulan dari beberapa instruksi yang kemudian dikumpulkan dalam suatu Function serta Class dengan fungsinya masing-masing yang bertujuan untuk mempermudah programmer untuk memanggil atau menggunakannya tanpa menulis syntax yang sama sehingga dapat mempersingkat waktu pengerjaan [13] Sedangkan Framework Codeigniter adalah Framework yang digunakan dalam aplikasi berbasis web yang sifatnya Open Source yang dapat digunakan untuk membuat atau membangun aplikasi dengan bahasa pemrograman PHP yang bersifat dinamis [14]. selain dikarenakan sifatnya yang Open Source alasan lain menggunakan Framework ini dikarenakan faktor keamanan, menurut Ainol Yaqin, Codeigniter memiliki kemanan yang cukup baik dikarenakan berbasis Framework [15]. Dari penjelasan di atas maka tujuan penulis melakukan penelitian ini, diharapkan sistem informasi yang dirancang menyajikan informasi dalam bentuk geografis mengenai data penyebaran lokasi pelatihan yang dilatih oleh BBPLM Jakarta, Kementerian Desa, PDT, dan Transmigrasi dalam bentuk WebGIS, yang bertujuan untuk mempermudah penentuan lokasi pelatihan berikutnya dengan acuan dari aplikasi tersebut.

\section{METODOLOGI PENELITIAN}

\subsection{Metodologi Pengembangan Software}

Banyak metodologi yang dapat digunakan untuk mengembangkan sebuah perangkat lunak, sistem informasi alumni pelatihan berbasis WebGIS ini dirancang dengan metodologi waterfall. Metode ini dipilih dikarenakan alur metodenya dijalankan secara bertahap sehingga tidak terfokus di tahapan tertentu. Gambar 1 menunjukan metodologi yang dimanfaatkan untuk membangun sistem informasi WebGIS ini.

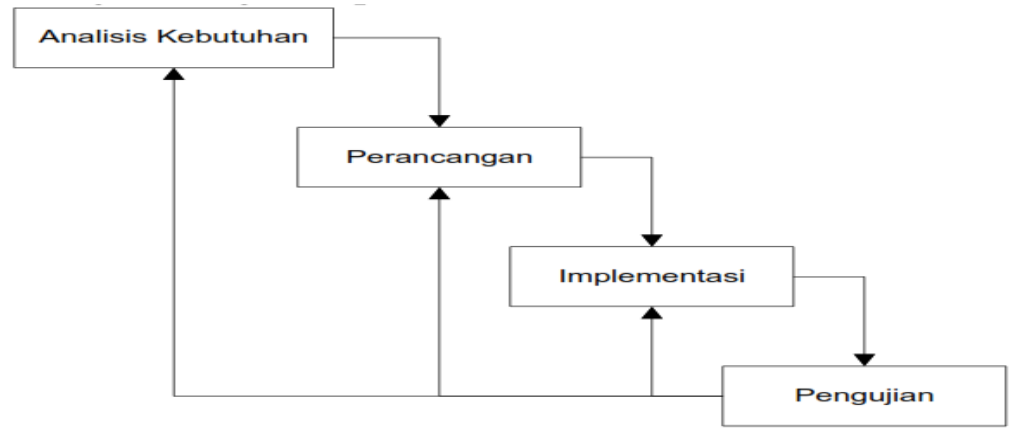

Gambar 1. Metodologi Waterfall yang Digunakan untuk Membangun Sistem

\subsection{Analisa Kebutuhan Data}

Pada tahap analisis kebutuhan, dilakukan analisis dengan cara wawancara dengan pihak penyelenggara pelatihan mengenai data dukung yang dimiliki serta fitur apa saja yang dibutuhkan, dengan cara ini penulis dapat menentukan komponen apa yang nantinya dibutuhkan untuk membangun sistem. Dengan adanya sistem baru ini diharapkan dapat meningkatkan efisiensi dalam menentukan lokasi pelatihan dengan data acuan yang ditampilkan dalam bentuk peta sehingga mempermudah dalam pemilihan lokasi pelatihan yang akan datang. Kemudian akan dilakukan pengumpulan data spasial dan data atribut atau data alumni pelatihan sebagai data yang nantinya akan 
JURNAL MEDIA INFORMATIKA BUDIDARMA

Volume 4, Nomor 3, Juli 2020, Page 659-665

ISSN 2614-5278 (media cetak), ISSN 2548-8368 (media online)

Available Online at https://ejurnal.stmik-budidarma.ac.id/index.php/mib

DOI 10.30865/mib.v4i3.2190

digunakan untuk merancang aplikasi, setelah data telah diperoleh maka tahapan selanjutnya adalah perancangan sistem yang nantinya akan diimplementasikan.

\section{HASIL DAN PEMBAHASAN}

Analisis sistem merupakan tahapan dimana akan dilakukan aktivitas untuk melakukan identifikasi serta evaluasi terhadap setiap user, dalam sistem ini terdapat dua hak akses yaitu admin dan $u s e r$ biasa. Berikut adalah penjabaran dari masing-masing user.

a. Admin, admin dapat melakukan penginputan data pelatihan beserta komponen-komponen data pelatigan seperti lokasi pelaksanaan pelatihan, laporan pelatihan, serta deskripsi singkat dari pelatihan.

b. User dapat melihat data persebaran pelatihan, mensortir persebaran pelatihan berdasarkan jenis pelatihan, meliha detail data pelatihan, melakukan pencarian untuk melihat persebaran pelatihan pada lokasi tertentu.

Dari analisa diatas maka dihasilkan spesifikasi sistem berupa model proses dan model data. Model proses dgambarkan dengan diagram Use Case seperti pada Gambar 2 sedangkan desain model data digambarkan melalui Entity Relationship Diagram (ERD) seperti yang ditampilkan pada Gambar 3.

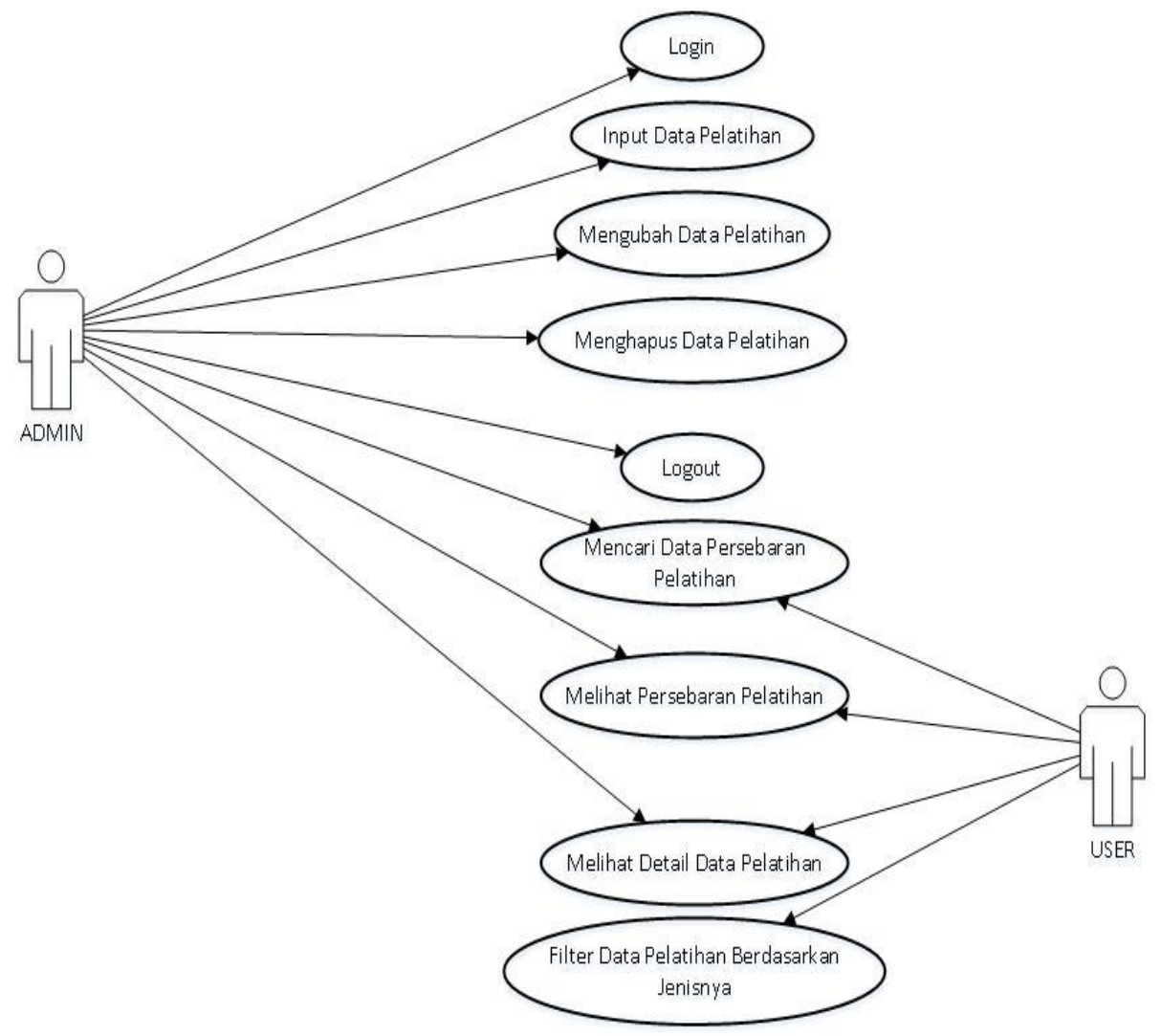

Gambar 2. Use Case Diagram Sistem Informasi Penyebaran Lokasi Pelatihan

Desain pada Gambar 2 menggambarkan Use Case dari sistem informasi penyebaran lokasi pelatihan. Terdapat 2 user yaitu Admin dan User Biasa, pada Use Case diatas Admin dapat melakukan 8 aktifitas yaitu, login, Input Data Pelatihan, Mengubah Data Pelatihan, Menghapus Data Pelatihan, Logout, Mencari Data Persebaran Pelatihan, Melihat Data Persebaran Pelatihan, dan Melihat Detail data Pelatihan. Sementara itu User Biasa dapat melakukan 4 aktifitas yaitu, Mencari Data Persebaran Pelatihan, Melihat Persebaran Pelatihan, Melihat Destail Data Pelatihan, Filter Data Pelatihan Berdasarkan Jenisnya.

Setelah menyelesaikan Use Case Diagram maka langkah selanjutnya yaitu melakukan perancangan, hal yang dilakukan dalam tahapan perancangan yaitu pembuatan Entity Relationship Diagram kemudian penyusunan table-tabel dalam pembuatan WebGIS serta membuat Activity Diagram. Dalam tahapan penyusunan Entity Relationship Diagram akan ditentukan bagaimana desain databse kemudian pada bagian ini juga akan ditentukan bagaimana hubungan antara tabel yang menghubungkan antara tabel yang satu dengan table yang lainnya, pada umumnya hubungan antar tabel tersebut dihubungkan antara Primary Key dengan Foreign Key sehingga akan terjadi keterkaitan antara satu tabel dengan table yang lainnya, selain Primary Key dan Foreign Key tentunya dalam tahap ini juga ditentukan atribut-atribut beserta tipe datanya, untuk lebih jelasnya perancangan ERD ini sudah digambarkan pada Gambar 3. 
JURNAL MEDIA INFORMATIKA BUDIDARMA

Volume 4, Nomor 3, Juli 2020, Page 659-665

ISSN 2614-5278 (media cetak), ISSN 2548-8368 (media online)

Available Online at https://ejurnal.stmik-budidarma.ac.id/index.php/mib DOI $10.30865 /$ mib.v4i3.2190

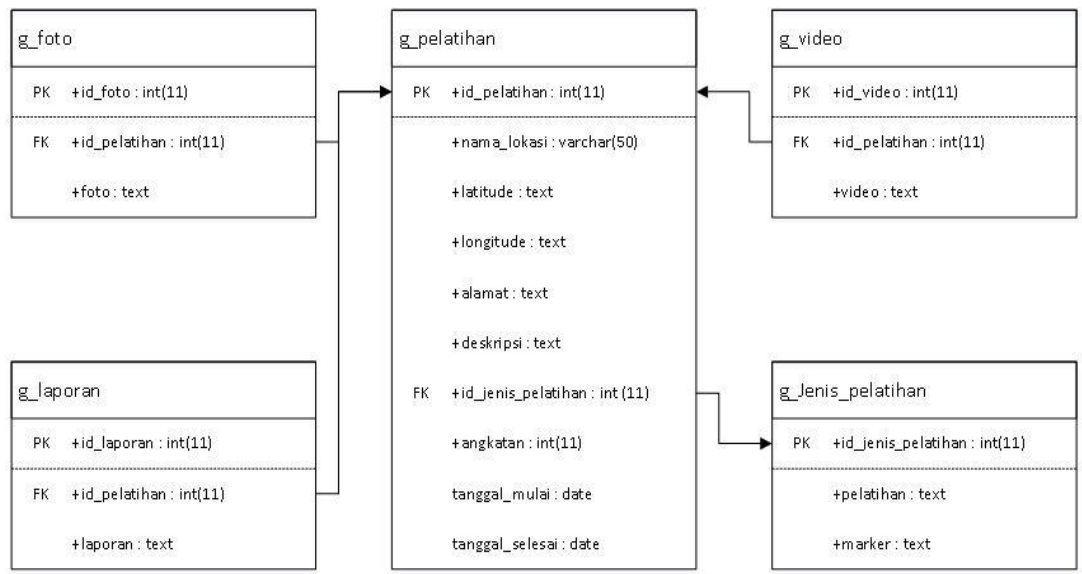

Gambar 3. Entity Relationship Diagram Sistem Informasi Penyebaran Lokasi Pelatihan

Perancangan selanjutnya yaitu membuat Activity Diagram, dalam tahapan ini akan dibahas bagaimana proses atau alur dari sistem yang dibuat, berikut adalah beberapa Acivity Diagram dalam perancangan sistem yang dibuat.

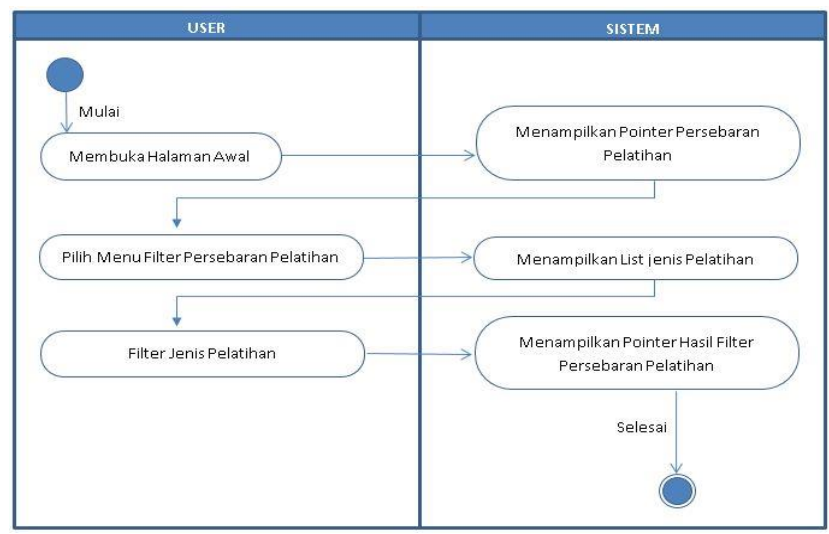

Gambar 4. Alur Proses Filter Data Persebaran Pelatihan

\subsection{Implementasi}

Implementasi dari hasil perancangan WebGIS ini adalah seperti Gambar 5.

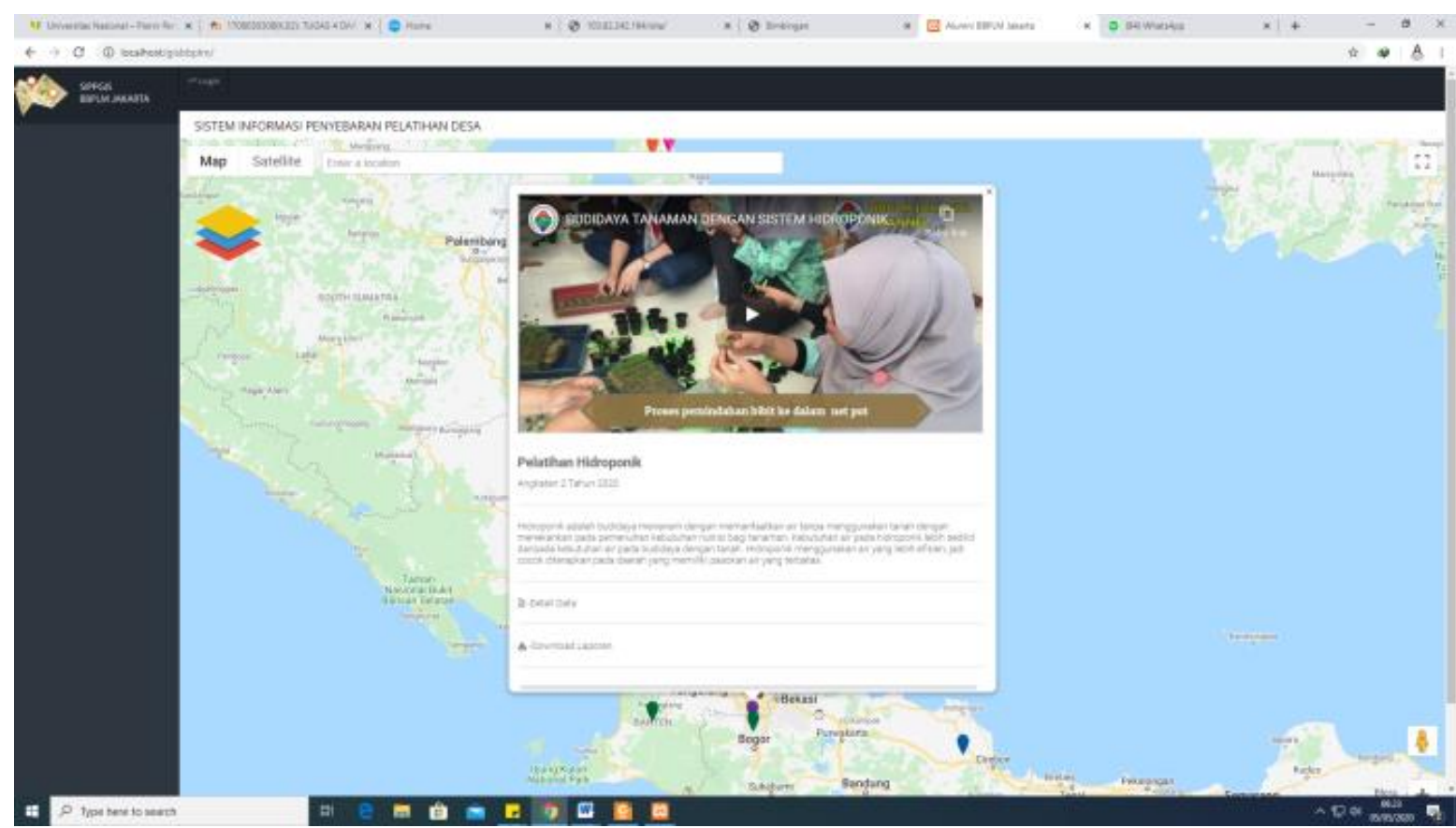

Gambar 5. Hasil Implementasi dari Perancangan 
JURNAL MEDIA INFORMATIKA BUDIDARMA

Volume 4, Nomor 3, Juli 2020, Page 659-665

ISSN 2614-5278 (media cetak), ISSN 2548-8368 (media online)

Available Online at https://ejurnal.stmik-budidarma.ac.id/index.php/mib

DOI 10.30865/mib.v4i3.2190

Gambar 5 merupakan hasil implmentasi dari perancangan yang merupakan halaman utama dari aplikasi yang dibuat, halaman utama yang menampilkan peta beserta pointer-pointer yang menandakan persebaran lokasi pelatihan, pointer-pointer tersebut memiliki warna yang berbeda-beda sesuai dengan jenis pelatihannya, selain itu jika pointer-pointer tersebut di klik maka akan menampilkan Pop Up yang akan menampilkan data dari pelatihan tersebut yang meliputi video pelatihan, nama pelatihan, deskripsi singkat, link untuk melihat detail data, dan link untuk mendownload laporan. Untuk tampilan detail data dapat dilihat pada Gambar 6.

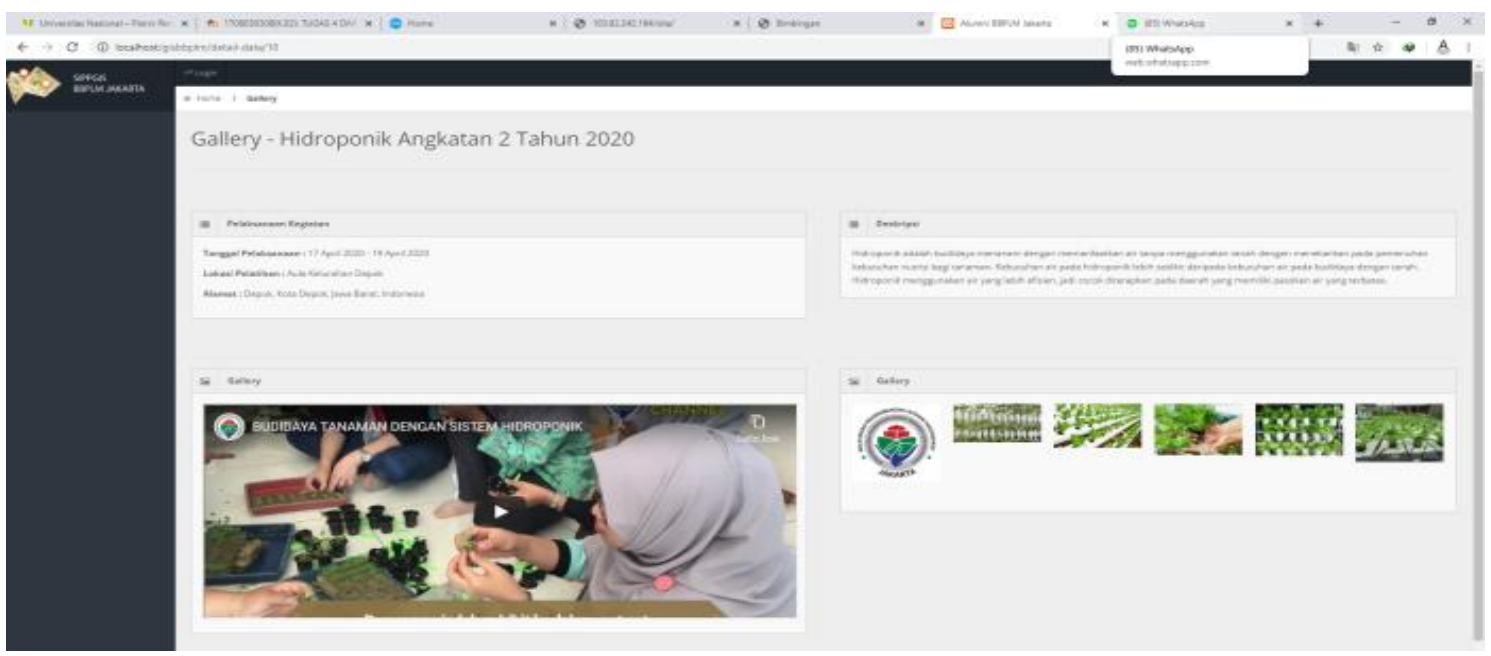

Gambar 6. Tampilan Detail Data

Selanjutnya yaitu menu admin, menu ini digunakan untuk memanajemen data dari aplikasi. Menu yang tersedia pada halaman admin yaitu menu Pelatihan, Gallery, Laporan, Video, dan Jenis Pelatihan, untuk tempilannya ditampilkan pada Gambar 7.

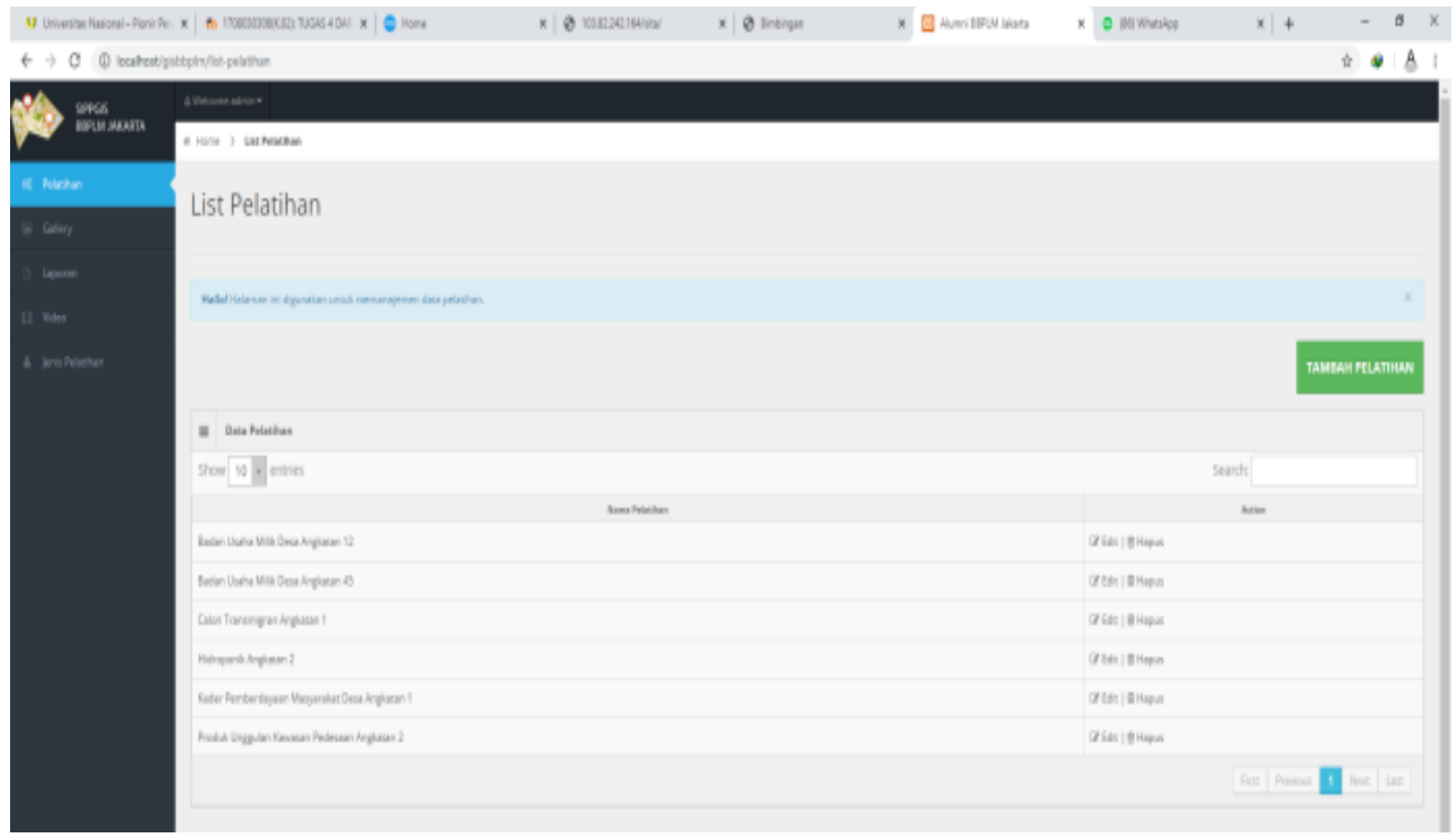

Gambar 7. Tampilan Menu Admin

Untuk menu Pelatihan digunakan untuk memanajemen data-data pelatihan, menu Gallery digunakan untuk memanajemen foto pelatihan, menu Laporan digunakan untuk memanajemen data laporan, menu video digunakan untuk memanajemen data video pelatihan, dan menu jenis pelatihan digunakan untuk memanajeman jenis pelatihan beserta jenis pointernya.

\subsection{Pengujian}

Untuk pengujian akan dilakukan menggunakan metode black box dimana pengujian ini digunakan untuk menguji fungsi dari masing-masing fitur yang ada pada perangkat lunak, modul User yang akan diuji coba yaitu modul halaman utama. Untuk hasil pengujian terhadap modul user dapat dilihat pada Tabel 1. 
Tabel 1. Pengujian Terhadap Halaman Utama

\begin{tabular}{llll}
\hline No. & Modul & Fungsi & Status \\
\hline 1 & Halaman Utama Website & Filter data berdasarkan Jenis Pelatihan & Proses Berhasil \\
2 & Halaman Utama Website & Pencarian daerah menggunakan fitur search & Proses Berhasil \\
3 & Halaman Utama Website & Menampilkan Pop Up data & Proses Berhasil \\
\hline
\end{tabular}

Setelah dilakukan pengujian terhadap fungsi yang tertera pada tabel 2, seluruhnya mendapatkan status berhasil, semua fungsi pada halaman utama dapat berjalan dengan baik. Untuk selanjutnya akan dibahas hasil uji coba terhadap modul admin yang meliputi modul untuk memanajemen data pelatihan, laporan, gallery, video, serta jenis pelatihan, untuk hasil uji coba akan dijelaskan pada tabel 2.

Tabel 2. Pengujian Terhadap Modul Pelatihan, Gallery, Laporan, Video, Jenis Pelatihan

\begin{tabular}{llll}
\hline No. & Modul & Fungsi & Status \\
\hline 1 & Pelatihan & Menampilkan Data, Input, Edit, Hapus Data Pelatihan & Proses Berhasil \\
2 & Gallery & Menampilkan Data, Input, Edit, Hapus Data Gallery/Foto & Proses Berhasil \\
3 & Laporan & Menampilkan Data, Input, Edit, Hapus Data Laporan & Proses Berhasil \\
4 & Video & Menampilkan Data, Input, Edit, Hapus Data Video & Proses Berhasil \\
5 & Jenis Pelatihan & Menampilkan Data, Input, Edit, Hapus Data Jenis Pelatihan & Proses Berhasil \\
\hline
\end{tabular}

Setelah dilakukan pengujian terhadap fungsi yang tertera pada tabel 2, seluruhnya mendapatkan status berhasil, proses memanajemen data Pelatihan, Gallery, Laporan, Video, Jenis Pelatihan yang meliputi proses menampilkan data, penginputan data, pengeditan data, serta penghapusan data dapat dilakukan dengan baik.

\section{KESIMPULAN}

Aplikasi WebGIS ini dikembangkan menggunakan PHP, Bootstrap, serta Google API yang dipadukan menggunakan Framework Codeigniter. Aplikasi WebGIS ini dapat menampilkan persebaran pelatihan yang telah dilakukan oleh Balai Besar Pengembangan Latihan Mayarakat Jakarta dengan memanfaatkan Google Maps sebagai peta dasar dan pointer untuk titik penyebaran lokasi pelatihan. Website ini juga bersifat dinamis dikarenakan sudah memanfaatkan penyimpanan dengan database sehingga website lebih mudah untuk dilakukan update data. Harapannya aplikasi ini mampu memetakan lokasi pelatihan dengan baik dan informatif shingga mampu membantu pemerintah untuk mengambil kebijakan dalam penentuan lokasi pelatihan desa berikutnya.

\section{REFERENCES}

[1] Herdisesel Santoso, et al., "Web E-Commerce Pada Toko Buku Umat untuk Meningkatkan Evektifitas Pemasaran," Jurnal Penelitian dan Pengabdian Masyarakat, vol. 7, no.2, pp.269-279, Juni 2019.

[2] Y. Trimarsiah, Muhajir Arafat, "Analisis dan Perancangan Website sebagai Sarana Informasi pada Lembaga Bahasa Kewirausahaan dan Komputer AKMI Baturaja,” Jurnal Ilmiah MATRIK., vol. 19, no. 1, pp.1-10, April 2017.

[3] R. Aminullah, Andri Suprayogi, Abdi Sukmono, "Aplikasi PGROUTING untuk Penentuan Rute Alternatif menuju Wisata Batik di Kota Pekalongan Berbasis WebGIS," Journal Geodesi Undip, vol. 7, no. 1, pp. 109-119, Januari 2018.

[4] M. Sholikhan, Sri yulianto Joko Prasetyo, Kristoko Dwi Hartomo, "Pemanfaatan WebGIS untuk pemetaan Wilayah Rawan Longsor Kabupaten Boyolali dengan Metode Skoring dan Pembobotan," Jurnal Teknik Informatika dan sistem Informasi, vol. 5, no. 1, pp. 131-143, April 2019.

[5] M. Bagus Salim, et al.,"Desain Aplikasi Peta Desa Katonsari, Kecamatan Demak, Kabupaten Demak Berbasis WebGIS," Jurnal Geodsi Undip, vol. 7, no. 2, pp. 42-52, April 2018.

[6] Z. Zheng, Z.Y. Chang, and Y.F. Fei, "A Simulation-as-a-services Framework Facilitating WebGIS Based Instalation Planning," The International Archives of the Photogrammety, Remote Sensing and spatial Information Science, vol. 42, no. 2, pp. 193-198, 2017.

[7] Y. Kuka, P. Ameti, and T. Bandrova, "GIS/GPS Solutions as Efficient Tools for Sustainable Management of Vineyards in Kosovo," Geodesy and Cartography, vol. 45, no. 1, pp. 28-36, 2019.

[8] A. Fitria, Nia. P, "Perancangan Sistem Informasi Pengolahan Data Praktek Kerja Lapangan (PKL) pada Devisi Humas PT. Pegadaian,” Jurnal Intra-Tech, vol. 2, no. 2, pp. 12-26, Oktober 2018.

[9] A. Naskov, "Smart City WebGIS Application: Proof of Work Concept for High-Level Quality-of-Services Assurance," International Society for Photogrammetry and Remote Sensing, vol. 4, pp. 99-106, 2018.

[10] Douglas K, Alinaswe S, "Evolution of PHP Application : A Systematic Literature Review,"International Journal of Recent Contributions from Engineering, Science \& IT, vol. 5, no. 1, pp. 28-39, 2017.

[11] Kirana Dwi Putri Siwi, Agung Triayudi, Sumiati “Aplikasi E-Ticketing Pariwisata di Kabupaten Serang Berbasis WEB," Prosiding Seminar Nasional Rekayasa Teknologi Informas, vol. 1, no. 1, pp. 189-195, November 2018.

[12] Surahmat, Alfred T, "Evaluasi Penggunaan Aplikasi Office Berbasis Open Source pada SMKN Kota Palembang dengan Pendekatan Technology Acceptence Model,” Jurnal SISFOKOM, vol. 7, no. 2, pp. 98-103, September 2018.

[13] Destinigrum M, Qhadili J A, "Sistem Informasi Penjadwalan Dokter Berbasis WEB dengan Menggunakan Framework Codeigniter (Studi Kasus : Rumah Sakit Yukum Medical center)," Jurnal TEKNOINFO, vol. 11, no. 2, pp. 30-37, 2017.

[14] Herriyanto B D, Kurniawan I K, Taufik I, "Sistem Aplikasi Perpustakaan Berbasis Web Menggunakan Framework Codeigniter pada SMAS Islamic Center,” Jurnal Ilmiah SISFOTENIKA, vol. 7, no. 2, pp. 187-196, Juli 2017. 
JURNAL MEDIA INFORMATIKA BUDIDARMA

Volume 4, Nomor 3, Juli 2020, Page 659-665

ISSN 2614-5278 (media cetak), ISSN 2548-8368 (media online)

Available Online at https://ejurnal.stmik-budidarma.ac.id/index.php/mib

DOI 10.30865/mib.v4i3.2190

[15] M. Ainol Y, Abdullah A A, "Sistem Advice Planing Online dengan Framework Codeigniter Berbasis WEB Bootstrap (Studi Kasus : Kabupaten Probolinggo),” Jurnal Pengembangan IT (JPIT), vol. 3, no. 2, pp. 219-224, Mei 2018. 